University of Wollongong

Research Online

Faculty of Engineering and Information

Faculty of Engineering and Information

Sciences - Papers: Part A

Sciences

$1-1-2014$

\title{
An algebraic approach for determination of DG parameters to support voltage profiles in radial distribution networks
}

Kashem M. Muttaqi

University of Wollongong, kashem@uow.edu.au

An D. T Le

University of Tasmania, dtale@utas.edu.au

Michael Negnevitsky

University of Tasmania, michael.negnevitsky@utas.edu.au

Gerard Ledwich

Queenstand University of Technology, g.ledwich@qut.edu.au

Follow this and additional works at: https://ro.uow.edu.au/eispapers

Part of the Engineering Commons, and the Science and Technology Studies Commons

Research Online is the open access institutional repository for the University of Wollongong. For further information contact the UOW Library: research-pubs@uow.edu.au 


\title{
An algebraic approach for determination of DG parameters to support voltage profiles in radial distribution networks
}

\begin{abstract}
Rapidly increasing electricity demands and capacity shortage of transmission and distribution facilities are the main driving forces for the growth of Distributed Generation (DG) integration in power grids. One of the reasons for choosing a DG is its ability to support voltage in a distribution system. Selection of effective DG characteristics and DG parameters is a significant concern of distribution system planners to obtain maximum potential benefits from the DG unit. This paper addresses the issue of improving the network voltage profile in distribution systems by installing a DG of the most suitable size, at a suitable location. An analytical approach is developed based on algebraic equations for uniformly distributed loads to determine the optimal operation, size and location of the DG in order to achieve required levels of network voltage. The developed method is simple to use for conceptual design and analysis of distribution system expansion with a DG and suitable for a quick estimation of DG parameters (such as optimal operating angle, size and location of a DG system) in a radial network. A practical network is used to verify the proposed technique and test results are presented.
\end{abstract}

\section{Keywords}

voltage, support, radial, distribution, networks, profiles, parameters, algebraic, dg, determination, approach

Disciplines

Engineering | Science and Technology Studies

\section{Publication Details}

K. M. Muttaqi, A. D. T. Le, M. Negnevitsky \& G. Ledwich, "An algebraic approach for determination of DG parameters to support voltage profiles in radial distribution networks," IEEE Transactions on Smart Grid, vol. 5, (3) pp. 1351-1360, 2014. 


\title{
An Algebraic Approach for Determination of DG parameters to Support Voltage Profiles in Radial Distribution Networks
}

\author{
K.M. Muttaqi, Senior Member, IEEE, An D.T. Le, Student Member, IEEE, M. Negnevitsky, Senior \\ Member, IEEE, and G. Ledwich, Senior Member, IEEE
}

\begin{abstract}
Rapidly increasing electricity demands and capacity shortage of transmission and distribution facilities are the main driving forces for the growth of Distributed Generation (DG) integration in power grids. One of the reasons for choosing a DG is its ability to support voltage in a distribution system. Selection of effective DG characteristics and DG parameters is a significant concern of distribution system planners to obtain maximum potential benefits from the DG unit. This paper addresses the issue of improving the network voltage profile in distribution systems by installing a DG of the most suitable size, at a suitable location. An analytical approach is developed based on algebraic equations for uniformly distributed loads to determine the optimal operation, size and location of the DG in order to achieve required levels of network voltage. The developed method is simple to use for conceptual design and analysis of distribution system expansion with a DG and suitable for a quick estimation of DG parameters (such as optimal operating angle, size and location of a DG system) in a radial network. A practical network is used to verify the proposed technique and test results are presented.
\end{abstract}

Index Terms - Distributed Generation, DG Placement, DG Size, DG Operation, Radial Networks, Voltage Support.

\section{INTRODUCTION}

$\mathrm{R}$ APIDLY increasing needs for electrical power and difficulties in providing required capacity using traditional solutions, such as transmission network expansions and substation upgrades, provide a motivation to select a Distributed Generation (DG) option. DG can be integrated into distribution systems to improve voltage profiles, power quality and system efficiency, and to reduce power losses, while

This research has been financially supported by the Australian Research Council under ARC Linkage Grant LP0560917, collaboration with Aurora Energy, Tasmania.

A/Prof. Kashem M. Muttaqi is with the Australian Power Quality and Reliability Centre at the School of Electrical Computer \& Telecommunications Engineering, University of Wollongong, New South Wales, Australia, Ms. An D.T. Le and Prof. Michael Negnevitsky are with the Centre for Renewable Energy and Power Systems at the School of Engineering, University of Tasmania, Hobart, Australia, and Prof. Gerard Ledwich is with the School of Engineering Systems, Queensland University of Technology, Brisbane, Australia, (emails: kashem@uow.edu.au; dtale@utas.edu.au; g.ledwich@qut.edu.au). avoiding significant investments in transmission and distribution systems [1-2]. From the distribution utility's point of view, the DG solution may be more economical as it provides the system with a higher supply capacity and an additional power reserve. From the customer's prospective, it provides an alternative source that can help fulfill requirements of growing power demands, improve reliability of power supply as well as reduce the cost of electricity during peak hours [3]. Generally, a DG system is defined as an electric power source of a limited size, from a few $\mathrm{kW}$ to a few MW, connected directly to the distribution level at a substation, a distribution feeder, or at a customer level [4]. DG includes renewable energy technologies such as bio-diesel, small hydro, etc, and non-renewable technologies include micro turbines, gas turbines, internal combustion engines, etc [5]. Recently, new advances in the DG technologies have lowered the cost and considerably widened DG application areas. In future, DG units are expected to play even more important roles in distribution systems [6].

There are four key reasons why DG would be an attractive option in distribution systems. Firstly, when the loading capacity of a long line is exceeded only for a small fraction of the time, then local generation can reduce the line overload as well as provide voltage support [4]. Secondly, when a long line is exceeding the prescribed voltage drop limits in spite of several series regulators, and the speed of response of these series regulators can produce excessively long periods of severe voltage excursions [8]. Primarily motivated by the voltage regulation problems in long rural lines, Ergon Energy, a distribution company, responsible for the vast areas of country Queensland, installed a $1 \mathrm{MW}$ generator to support voltage in Alpha feeder. Thirdly, DG might exist because of reliability and voltage quality. DG can enhance reliability of the power supply and improve voltage quality [21]. As an example, Endeavour Energy, another power distribution utility in New South Wales, has installed a DG to improve reliability and voltage quality for Cattai feeder. Lastly, DG can be used for peak-shaving and support network including improving feeder voltage, reducing power losses, and deferring augmentation of transmission and distribution (T\&D) infrastructure [12]. Endeavour Energy has realized the benefits 
of DG installation to support Ulladullah feeder voltage especially during holiday periods. In many of these examples, the exact location and size of the DG for line relief or voltage regulation can be enhanced by an evaluation of the DG parameters from the voltage control view-point.

For different DG technologies, various constraints are to be taken into account. Depending on these constraints, distribution system engineers can select and operate DG units in the most effective manner. In [7], an expression for determining the DG size for the maximum permissible voltage is derived as a function of the DG distance from the substation. Loads are assumed to be uniformly distributed. The authors in [8] presented a control model to utilize a DG as a voltage support for a single wire earth return systems; the controller is developed based on the line voltage sensitivity model. In [9], a heuristic cost-benefit analysis approach is developed to determine the DG size and its location based on the minimization of investment and operating cost criteria. Another technique to decide the DG size and its placement has been proposed in [10]; this technique allows a distribution system planner to optimize the DG size and its placement on the network design. The authors in [11] have developed an integrated distribution system planning model based on cost optimization. In [12], authors have presented a method for multiple DG placements in a distribution network for minimizing power losses. In [13], a method for optimal location of DG in a meshed electric power system is presented. Authors of [14] have established a method to determine a suitable DG location to minimize the voltage deviation of the feeder from the reference level as well as minimize the number of DG units required. However, the idea of keeping the system voltage close to the reference voltage can lead to a very expensive solution, especially when the feeder is long and load demand is high. Pandi et al [16] have proposed an optimization method to determine the maximum penetration level of utility owned DG system. The proposed method [16] has used the harmonic and protection coordination as a bench mark. In [17], the benefit of installing DG is discussed and a multi-objective optimization approach is proposed for optimal allocation of the DG in the networks. Authors in [18] have presented a Kalman filter based technique for determining optimal locations and sizes of multiple DG units to minimize total power loss in the system. A decentralized voltage control approach is proposed in [19] to provide short- and long-term voltage support in distribution networks. The authors in [19] have also developed a strategy for identifying voltage control zone for the DG. In [20], an analysis is carried out for voltage profile related problems introduced by different locations, sizes and types of the DG units in load-voltage distribution. Authors in [21], have discussed about the profit from DG investment for both, utility and DG owners. In [22], an overview of the state of the art models and methods applied to determine optimal DG size and location is presented, and current and future research trends in this field are discussed.

In this paper, an optimal operating angle of a synchronous machine type DG is determined based on the network voltage sensitivity. The desirable phase angle of the current injection of the DG relative to the local voltage is determined. An analytical method is developed to determine the most suitable size and location of the DG to provide a required level of voltage support in radial systems. The proposed method uses an algebraic approach that provides the solution with minimum computational efforts and guides for conceptual design and analysis for realistic distribution system expansion with a DG. Simulations to demonstrate the effectiveness of the proposed method are carried out on a practical test system.

\section{DG Operation BASED ON Voltage Sensitivity}

In this paper, we assume that the DG units are either fully operated by the utility, or belong to customers but are allowed to run to address the needs of the network in regard to the voltage support. Thus, an optimal selection of the DG parameters is decided so that the required voltage levels can be obtained with the lowest capital cost of the DG. The DG is assumed to be a synchronous machine type that provides the required level of reactive power. Also, we assume that it would be possible to locate a DG at any place in the feeder. The optimal phase angle of the DG current can be determined by applying the Thevenin principle. Fig. 1 shows the equivalent diagram of the system looking from the point of the DG common coupling. The DG is considered as a controlled ideal current source in the distribution system.

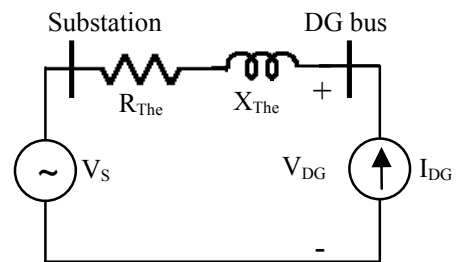

Fig. 1: Thevenin equivalent of a system with DG

In Fig. $1, R_{\text {The }}+j X_{\text {The }}=Z_{\text {The }}$, is the Thevenin equivalent impedance of the system looking from the DG connection point. According to Fig. 1, the voltage at the DG connection point, $V_{D G}$ can be calculated as:

$$
V_{D G}=I_{D G}\left(R_{\text {The }}+j X_{\text {The }}\right)+V_{S}
$$

Equation (1) can be rewritten in phasor form as,

$$
V_{D G}=\left|I_{D G} \| Z_{\text {The }}\right| \angle \beta+V_{S}
$$

where, $\beta=\theta_{D G}+\tan ^{-1}\left(X_{\text {The }} / R_{\text {The }}\right)$, and $\theta_{D G}$ is the phase angle of the DG current with respect to the local Thevenin voltage. Equation (2) can be represented graphically as shown in Fig. 2.

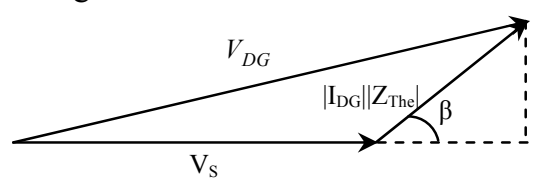

Fig. 2: Phasor diagram of voltage at DG connection point

Assume that DG is placed at a fixed location with the output of a fixed current magnitude. Thus, $Z_{T h e}$ and $\left|I_{D G}\right|$ are constant, and $\theta_{D G}$ is the only variable. According to Fig. 2 , the voltage magnitude at the DG connection is maximum for $\beta=0$. In other words, the optimal phase angle of the DG is 
$\theta_{D G}=-\tan ^{-1}\left(X_{\text {The }} / R_{\text {The }}\right)$.

Let us assume that the local voltage at the DG connection point is $V_{D G}=\left|V_{D G}\right| \angle \alpha_{D G}$. We have $V_{D G} I_{D G}^{*}=P_{D G}+j Q_{D G}$, where $P_{D G}$ and $Q_{D G}$ are the real and reactive power injections from the DG. Since the sensitivity ratio is defined as $s_{V}=P_{D G} / Q_{D G}$, the phase angle of the DG output current in terms of the phase angle of local voltage will be $\theta_{D G}=\alpha_{D G}-\tan ^{-1}\left(1 / s_{V}\right)$.

When a DG produces only reactive power, the phase angle of the DG output current is $\pi / 2$ (radians) leading the phase angle of the local voltage. When the DG operates optimally (which means the ratio of $P_{D G}$ and $Q_{D G}$ is equal to $s_{V}$ ), the DG current is lagging the local voltage by $\tan ^{-1}\left(1 / s_{V}\right)$ radians. The DG operating condition, which represents the ratio of active to reactive power injection from the $\mathrm{DG}$, is set to inject the optimal real and reactive power to maximize the voltage support. When a fuel cost becomes a dominant factor, the lowest capital plus operating cost solution becomes more "reactive" and a new optimal value for power factor is necessary.

There are two limits on the reactive power of a synchronous generator based DG. These are VAr injection (positive) and VAr absorption (negative) limits. In this paper, a DG is used for voltage support as well as peak shaving. In either case, a DG should not be required to run in the VAr injection mode. Therefore, the negative reactive power limit is not discussed in this paper, and hence we should concentrate on the positive reactive power limit only.

In power systems, a generally accepted rule is that a generator should operate with power factor in the range from 0.85 lagging to unity and produce reactive power with a given real power to its full $\mathrm{kVA}$ capacity $\left(\mathrm{kVA}_{\text {rated }}\right)$ [15]. In other words, the $\mathrm{kVAr}$ limit is equal to $\sqrt{\left(k V A_{\text {rated }}\right)^{2}-(k W)^{2}}$. In those cases where the optimal power factor is smaller than 0.85 , it is necessary that a DG with appropriate $\mathrm{kVAr}$ limit (i.e. appropriate field or armature winding heating) at that particular power factor is selected in order to meet the requirements.

It should be noted that a DG that is used for voltage support may only be required to operate several hours a week (during high demand periods) or during peak hours only. Thus, the DG capital cost may have much higher impact on the overall expenditure than its operating cost. In other words, if the usage of the DG is limited to a number of hours per year, the dominant cost will be determined by the DG kVA rating. Therefore, our primary objective is to find a DG with the minimum kVA rating, which would be just enough to support the required voltage levels. It has been found that in many cases, the injection mode of both real $(\mathrm{P})$ and reactive $(\mathrm{Q})$ power will result in a smaller value of $\mathrm{kVA}$ required (and thus smaller capital cost of the DG) than the DG size with the injection mode of reactive power only [8]. Thus, the injection of both $\mathrm{P}$ and $\mathrm{Q}$ should have a lower total cost, although operating costs may become higher than that of the larger DG with the Q injection only. Therefore, we have considered the injection of real and reactive power of the DG for voltage support at a fixed power factor.

In summary, when the annualized fuel cost is low, a DG is operated to inject real and reactive power with the power factor that matches voltage sensitivity of lines. The optimal power factor of the DG will decrease with the increase of the fuel cost [8]. In other words, the DG operating angle has been locked at the point of maximum voltage sensitivity. In case of high fuel cost, optimal operation with low power factor solution may dictate reactive power injection and reactive power limit can be reached.

\section{Proposed Algebraic Method for Determining DG SIZE AND LOCATION ON A RADIAL FEEDER}

In this section, an algebraic method for determining the optimal size and location of a DG on a radial feeder is developed.

Consider a distribution system with $\mathrm{N}$ load buses. These buses are denoted from bus 1 to bus $n$, from the supply end to the remote end of a feeder, respectively. The relationship between voltages and currents in the system is as follows [8]:

$$
\mathbf{Y}_{\text {bus }} \mathbf{V}_{\text {bus }}=\mathbf{I}_{\text {bus }}
$$

where, $\mathbf{Y}_{\text {bus }}$ is the impedance matrix for N-bus system, $\mathbf{V}_{\text {bus }}$ is the vector of voltages for bus 1 to bus $n$, and $\mathbf{I}_{\text {bus }}$ is the vector of external currents for bus 1 to bus $n$.

Equation (3) can be rewritten as:

$$
\left[\begin{array}{ll}
\mathbf{Y}_{\mathbf{A}} & \mathbf{Y}_{\mathbf{B}} \\
\mathbf{Y}_{\mathbf{B}}^{\mathbf{T}} & \mathbf{Y}_{\mathbf{D}}
\end{array}\right]\left[\begin{array}{c}
V_{S} \\
\mathbf{V}_{\mathbf{X}}
\end{array}\right]=\left[\begin{array}{c}
I_{S} \\
\mathbf{0}
\end{array}\right]
$$

where,

$$
\mathbf{Y}_{\mathbf{A}}=\left[\begin{array}{ll}
\mathrm{Y}_{1,1}
\end{array}\right] \quad \mathbf{Y}_{\mathbf{B}}=\left[\begin{array}{lll}
Y_{1,2} & \ldots & Y_{1, n}
\end{array}\right] \quad \mathbf{Y}_{\mathbf{D}}=\left[\begin{array}{ccc}
Y_{2,2} & \ldots & Y_{2, n} \\
\vdots & \ddots & \vdots \\
Y_{n, 2} & \ldots & Y_{n, n}
\end{array}\right]
$$

Thus, the source current $I_{S}$ and the voltages of the system without DG can be computed using (5) and (6), respectively:

$$
I_{S}=\left(\mathbf{Y}_{\mathbf{A}}-\mathbf{Y}_{\mathbf{B}} \mathbf{Y}_{\mathbf{D}}^{-1} \mathbf{Y}_{\mathbf{B}}^{\mathbf{T}}\right) V_{S}
$$

The voltages of the system without DG are,

$$
V_{X}^{i n i}=-\mathbf{Y}_{\mathbf{D}}^{-\mathbf{1}} \mathbf{Y}_{\mathbf{B}}^{\mathbf{T}} V_{S}
$$

\section{A. Voltages and Currents of the network without DG}

In the proposed approach, a distribution feeder is represented by a short line model, and the loads are uniformly distributed along the feeder. It should be noted that this is a commonly used assumption as used in [4], [8], [23], and is a useful approximation for many distribution network problems. Let us consider a radial system with the length of $L$. Assume that $z_{L}$ and $y_{L}$ are line impedance and load admittance per unit length, respectively. The diagram of the system is shown in Fig. 3, where $I_{S}$ and $V_{S}$ are the source current and source voltage, respectively, and $I_{R}$ and $V_{R}$ are the remote end current and voltage of the feeder, respectively.

Using Kirchhoff's current and voltage laws, the relationship between terminal voltage and current can be defined [24] as follows:

$\frac{V(x+\Delta x)-V(x)}{\Delta x}=z_{L} I(x)$ 
$\frac{I(x+\Delta x)-I(x)}{\Delta x}=y_{L} V(x+\Delta x)$

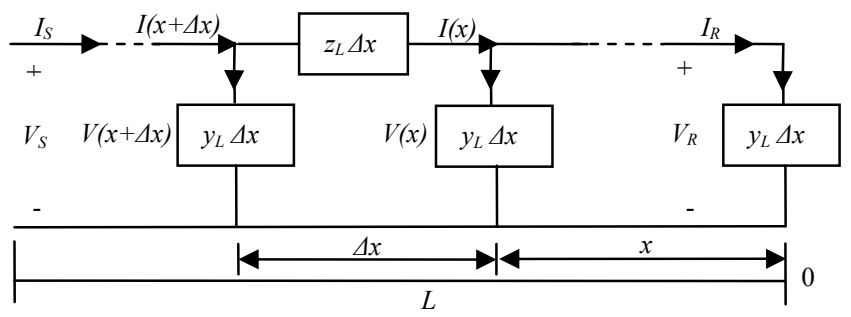

Fig. 3: Diagram of a radial distribution feeder

By applying the definition of the derivative with the feeder divided into infinitely small segments, and the loads uniformly distributed along the feeder (i.e. $\Delta \mathrm{x} \rightarrow 0$ ), we obtain:

$\frac{\partial^{2} V(x)}{\partial x^{2}}=\gamma^{2} V(x)$

$\frac{\partial^{2} I(x)}{\partial x^{2}}=\gamma^{2} I(x)$

where, $\gamma^{2}=z_{L} y_{L}$.

Assume that the solution of (9) is given by

$V(x)=A_{1} e^{\gamma x}+A_{2} e^{-\gamma x}$

where $\mathrm{A}_{1}$ and $\mathrm{A}_{2}$ are constants.

Since $I(x)=\left(1 / z_{L}\right) \int V(x) d x$, we obtain:

$I(x)=\frac{\gamma}{z_{L}}\left(A_{1} e^{\gamma x}-A_{2} e^{-\gamma x}\right)$

At the substation, the voltage is assumed to be constant and thus the current can be calculated by (5). Therefore, $V_{S}$ and $I_{S}$ are known.

With the boundary conditions at $x=x_{L}, V\left(x_{L}\right)=V_{S}$ and $I\left(x_{L}\right)=I_{S}$, where $x_{L}$ is the distance from the remote end to the source, we obtain the expressions of $V(x)$ and $I(x)$ in terms of $V_{S}$ and $I_{S}$ as follows:

$V(x)=\frac{V_{S}+\rho I_{S}}{2 e^{\gamma L}} e^{\gamma x}+\frac{V_{S}-\rho I_{S}}{2 e^{-\gamma L}} e^{-\gamma x}$

$I(x)=\frac{1}{\rho}\left(\frac{V_{S}+\rho I_{S}}{2 e^{\gamma L}} e^{\gamma x}-\frac{V_{S}-\rho I_{S}}{2 e^{-\gamma L}} e^{-\gamma x}\right)$

where, $\rho=\sqrt{z_{L} / y_{L}}$

Using (13) and (14), voltages and currents at any point in the feeder can be calculated. If voltage regulators are present in the system, their effects can be included by modeling them as transformers. The above approach is useful for DG planning, as it can provide a quick solution for voltage and current at a point with a reasonable level of approximation.

\section{B. Voltages and Currents of the network with $D G$}

To investigate DG impact on a feeder, the DG with output current of $I_{D G}$ and phase angle of $\theta_{D G}$ (with respect to the angle of $V_{S}$ ) is connected at a position $x=x_{k}$, as shown in Fig. 4. As mentioned earlier, the DG is represented as a current source. This representation is used for design purpose only. However, once the required current of the DG becomes known, an appropriately rated DG can be selected. For any desired power factor, the required peak current will determine the appropriate size of the DG.

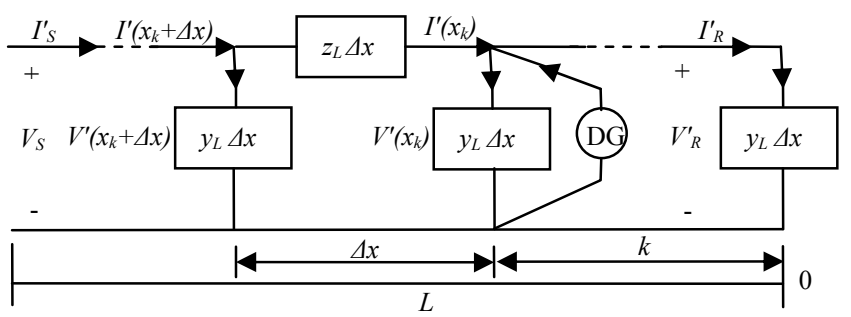

Fig. 4: Radial distribution feeder with a synchronous machine type DG

Without the DG, and using the short line model, the source current is equal to the total current drawn by the load. In other words, $I_{S}=I_{L}$, where $I_{S}$ and $I_{L}$ are the source current and total load current, respectively. When the DG is introduced into the network, the total load current becomes the summation of the output from two sources, i.e. $I_{S}^{\prime}+I_{D G}=I_{L}^{\prime}$, where $I_{S}^{\prime}$ and $I_{L}^{\prime}$ are the new source current and the new load current, respectively. Since the local voltage of the network with the DG is higher than that of the network without the DG, $I_{L}^{\prime}$ is smaller than $I_{L}$. However, as we consider that the DG is used for voltage support, the voltage variation before and after DG connection is relatively small. For the purpose of voltage drop calculation, $I_{L}^{\prime}$ is approximated by $I_{L}$. Therefore, the relation between the source current with the DG and source current without the DG is $I_{S}^{\prime} \approx I_{S}-I_{D G}$.

Real distribution loads are often approximated as a mixture of constant power and constant impedance loads. Over the very small range of voltage variation being considered (from the voltage without DG to the voltage with DG), the current change of the voltage dependent load is very small and the error can be neglected. For this reason, due to the DG connection, the current flow at the upstream (from the source to the DG location) is changed approximately by $I_{D G}$, while at the downstream (from the DG location to the remote end), the current flow remains almost the same as in the case without the DG. Therefore, with the DG inclusion, the line current has a step change at the DG connection and the system has to be solved separately for two different parts of the feeder: one is from the source to the DG location and the other is the DG location to the remote end of the feeder.

(i) Case 1: From the source to the DG location $\left(x_{k} \leq x \leq x_{L}\right)$ Similar to the case of the system without DG, we obtain the function of voltage and current in the general form as:

$V^{\prime}(x)=B_{1} e^{\gamma x}+B_{2} e^{-\gamma x}$

$I^{\prime}(x)=\frac{1}{\rho}\left(B_{1} e^{\gamma x}-B_{2} e^{-\gamma x}\right)$

With the boundary conditions at $x=x_{L}, V^{\prime}\left(x_{L}\right)=V_{S}$ and at $x=x_{k^{+}}, I^{\prime}\left(x_{k^{+}}\right)=I\left(x_{k}\right)-I_{D G}$, we obtain the expression of $B_{1}$ and $B_{2}$ as follows:

$B_{1}=\frac{\frac{V_{S}+\rho I_{S}}{2 e^{2 \gamma L}} e^{2 \gamma k}+\frac{V_{S}+\rho I_{S}}{2}-\rho I_{D G} e^{\gamma k} e^{-\gamma L}}{e^{\gamma L}+e^{2 \gamma k} e^{-\gamma L}}$ 
$B_{2}=\left(V_{S}-B_{1} e^{\gamma L}\right) e^{\gamma L}$

(ii) Case 2: From the DG location to the remote end $\left(x_{0} \leq x \leq x_{k}\right)$

The general functions of voltage and current are:

$V^{\prime}(x)=C_{1} e^{\gamma x}+C_{2} e^{-\gamma x}$

$I^{\prime}(x)=\frac{1}{\rho}\left(C_{1} e^{2 x}-C_{2} e^{-\gamma x}\right)$

At the DG connection point, voltages are related as $V^{\prime}\left(x_{k^{+}}\right)=V^{\prime}\left(x_{k^{-}}\right)=V^{\prime}\left(x_{k}\right)$.

The values of $C_{1}$ and $C_{2}$ can be determined as:

$C_{1}=\frac{B_{1} e^{2 \gamma k}+B_{2}+A_{1}-A_{2}}{e^{2 \gamma k}+1}$

$C_{2}=\frac{\left(B_{1}-A_{1}+A_{2}\right) e^{2 \gamma k}+B_{2}}{e^{2 \gamma k}+1}$

\section{Voltage Profile of a Radial System}

By taking the derivative of the voltage magnitude function with respect to distance $x$ and observing this, we can predict the trends of the system voltage profile (see Appendix for details) as pointed below.

- In the case without DG: If the derivative of the voltage magnitude with respect to $x$ is positive, the voltage will increase from the remote end $\left(x=x_{0}\right)$ towards the source $\left(x=x_{L}\right)$.

- In the case with DG:

- For $x_{0} \leq x \leq x_{k}$ : If $\partial\left|V^{\prime}(x)\right| / \partial x>0$, the voltage will increase from the point $x=0$ to the point $x=k$.

- Considering the interval between the source and the point $x=k$ :

* If $\partial\left|V^{\prime}(x)\right| / \partial x>0$ for all $x$, the voltage increases in the interval.

* If $\partial\left|V^{\prime}(x)\right| \partial x<0$ for all $x$, the voltage decreases in the interval.

* If $\partial \mid V^{\prime}(x) / \partial x$ is negative for some values of $x$ and positive for some other values of $x$, the voltage decreases in the interval $\left[x_{k}, x_{m}\right]$ and then increases in the interval $\left[x_{m}, x_{L}\right]$, where $x_{m}$ is referred to the point which has a minimum voltage value within the section from $x_{k}$ to $x_{L}$. The value of $x_{m}$ can be determined from the condition of $\left.\frac{\partial\left|V^{\prime}(x)\right|}{\partial x}\right|_{x=x_{m}}=0$.

\section{Optimizing the DG Size and its Placement}

According to the analysis of the voltage profile discussed in the previous section when the feeder is loaded beyond surge impedance level, the maximum voltage can occur either at the substation or at the DG connection point. The minimum voltage, on the other hand, frequently occurs at the remote end but can also occur at another point, say at $x_{m}$.

Different power utilities may use different standards to fulfill the requirements set for supply quality. Therefore, the voltage limits to be applied may vary from one case to another. In this paper, the DG is considered as an option for voltage support during the high loading condition. Thus, in most cases, DG inclusion for voltage compensation will not cause an over-voltage problem except perhaps at the DG terminal. However, generally, the optimal location of DG is close to the remote end. Thus, the voltage at the DG terminal is unlikely to be violated during the period of DG operation at peak time of the load. The main issue during high loading condition is to satisfy the minimum voltage requirement. If optimization of the DG location and size to maintain a minimum voltage causes over-voltage issues at the DG connection point, the usual solution would be to consider multiple injection points with multiple DG solution which can be solved using numerical approaches as discussed in $[4,12]$.

Let $V_{r}$ be the required lower voltage limit of the feeder, i.e. the reference voltage. In order to meet this voltage boundary, the DG size and location are found for the following 2 cases:

Case 1) If global minimum is at the remote end, the solution for the DG location $k$ and the DG size $\left|I_{D G}\right|$ can be determined numerically with sequential optimization once we set:

$$
\left|V^{\prime}\left(x_{0}\right)\right|=V_{r}
$$

Case 2) If global minimum is near to the mid-point rather than the remote end, the solution for the DG location $k$ and the DG size $\left|I_{D G}\right|$ is determined numerically with sequential optimization from the following equality:

$$
\left|V^{\prime}\left(x_{m}\right)\right|=V_{r}
$$

where $\left|V^{\prime}\left(x_{m}\right)\right|$, and $\left|V^{\prime}\left(x_{0}\right)\right|$ are the magnitudes of the feeder voltages at points $x_{m}$ and $x_{0}$, respectively, when the DG is present in the system.

In the sequential optimization, a function, $F(z)=0$ has been used, where $\mathrm{z}$ is a vector that contains the DG location $k$ and injection magnitude $\left|I_{D G}\right|$. In other words, $\mathrm{F}$ is a function of two variables $\left(k\right.$ and $\left|I_{D G}\right|$ ) which are both continuous variables. The advantage of the continuous variable compared to the discrete one normally used in numerical approaches is that the search will converge faster to an accurate solution. These two variables can be determined by using the numerical method called Trust-Region Dogleg as discussed in [25].

Equations (23) and (24) are established by assigning the predefined value of the $V_{r}$ to the algebraic expression of the reference voltage. Next, the suitable DG size and location are determined such that they satisfy either (23) for Case 1 or (24) for Case 2, provided that the smallest size of the DG is selected. The algorithm for the proposed algebraic method is shown in Fig. 5. As can be seen in Fig. 5, two possible solutions illustrated by two separate routines are considered in the proposed algorithm. If one solution is found to be invalid, it is disregarded and the other solution will be adopted.

The proposed approach can provide a single DG solution with the assumptions that the loads are uniformly distributed and DG is planned for network support only. It is worth noting 
that the proposed method offers a quick solution compared to numerical solutions available in the literature. It can also guide the network planners to develop conceptual design and analysis for network expansion with a DG system. In this approach, a single DG can be planned for a single feeder. Such a solution may be required for voltage support in cases with long distribution feeders and/or feeders with long laterals. If an exact and accurate solution is required, one can use a numerical approach for optimizing parameters of single or multiple DG with actual loads in a realistic network.

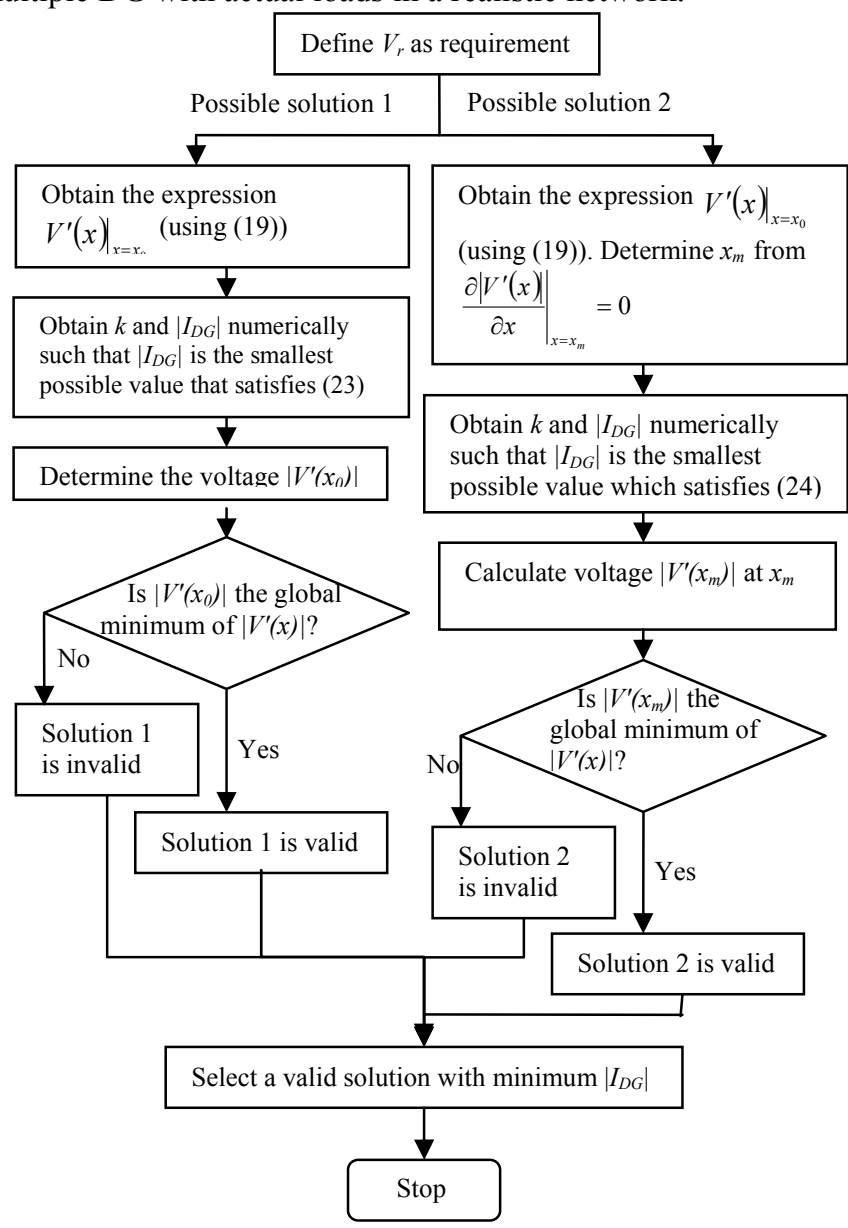

Fig.5: Flowchart for implementing the proposed algebraic approach

Using this method, it can be ensured that the voltage limit is taken into account for all points in the feeder. Therefore, no unexpected voltage drops (i.e. voltages lower than the specified voltage limit) will occur. Moreover, the solution can be obtained by solving a set of equations under specified constraints. The proposed algebraic method represents a simplified approach to solve the feeder voltage problem with $\mathrm{DG}$, and thus it is suitable for conceptual design and analysis for DG planning in radial distribution networks. The proposed approach provides a guideline to the utility for an efficient and logical way of determining the DG parameters which are reliable and effective for the distribution networks.

\section{RESULTS AND DisCUSSIONS}

The proposed algebraic approach has been extensively tested on a practical system, which is a long distribution feeder of Aurora Energy, a distribution utility of Tasmania. The length of the main feeder is $48 \mathrm{~km}$. As this feeder provides power to a low densely populated at rural area, even though it is considerably long, it does not have any backup substation and is thus a potential candidate of voltage support by a DG. There is only one tap changing transformer at the substation and one voltage regulator, far from the substation to boost up the line voltage.

The line impedance for the main feeder is $Z_{\text {line-main }}=$ $(0.6672+j 0.3745) \Omega / \mathrm{km}$ and for the laterals is $Z_{\text {line-lateral }}=$ $(0.5959+\mathrm{j} 0.3345) \Omega / \mathrm{km}$. The system also has a voltage regulator with the ratio of $1: 1.025$ located at $16 \mathrm{~km}$ far from the Smithton substation. It should be noted that the system has high $\mathrm{R} / \mathrm{X}$ ratio. The high $\mathrm{R} / \mathrm{X}$ ratio of the lines is a typical issue of long distribution line for rural supply in Australia. This is due to the fact that long line in rural area is designed with smaller size conductor to provide power in low density populated area. We consider the worst case scenario in regard to the load demand, which is $2.0 \mathrm{MVA}$ in total. At this loading level, DG support is required to achieve the required voltage limits.

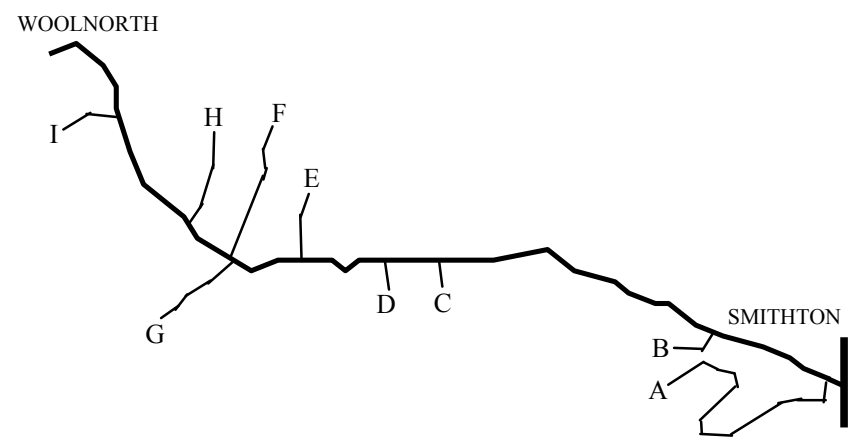

Fig. 6: The Smithton - Woolnorth test feeder

TABLE I

PARAMETERS OF LATERALS

\begin{tabular}{|c|c|c|c|}
\hline Lateral & Length (km) & $\begin{array}{c}\text { Distance from the substation } \\
(\mathbf{k m})\end{array}$ & $\begin{array}{c}\text { Total load } \\
(\mathbf{k V A})\end{array}$ \\
\hline A & 12.0 & 1.5 & 250.8 \\
\hline B & 2.5 & 6.0 & 104.5 \\
\hline C & 2.0 & 21.5 & 188.1 \\
\hline D & 2.0 & 24.0 & 100.0 \\
\hline E & 5.0 & 28.0 & 125.4 \\
\hline F & 9.0 & 31.0 & 52.2 \\
\hline G & 5.0 & 31.0 & 41.8 \\
\hline H & 6.0 & 33.5 & 40.0 \\
\hline I & 4.0 & 43.0 & 83.6 \\
\hline
\end{tabular}

To validate the proposed method, we have applied them to the following cases:

- Simplified system (the feeder without laterals): It is a modified form of the practical system shown in Fig. 6. All laterals are ignored and the system is represented as a single feeder with uniformly distributed load of 2.0 MVA in total. The line impedance of the feeder is $Z_{\text {line }}=(0.6672$ $+\mathrm{j} 0.3745) \Omega / \mathrm{km}$. Nominal substation voltage $\mathrm{V}_{\mathrm{S}}$ is $22 \mathrm{kV}$, Thevenin source impedance, $Z_{S}$ is $(0.7278+j 2.6802) \Omega$. 
- Actual system (the feeder with all laterals): It is an actual representation of a practical system shown in Fig. 6. The main feeder is $48 \mathrm{~km}$ long and has 1.0136 MVA load. There are nine laterals attached to the main. Their features are described in Table I.

\section{A. Optimal Operation of $D G$}

Simulations are conducted with a DG integrated in the test system to investigate an improvement in the voltage profile of the system. The MVA base is $1 \mathrm{MVA}$ and voltage base is 22 $\mathrm{kV}$ used in the simulations. The voltage at the source is 1.0 per-unit (pu). A synchronous type of DG is used so that its operating angle can be adjusted. The optimal phase angle of the DG current, and thus the optimal operating angle of the DG, is determined accordingly to each DG location considered, using the method discussed in Section II. The parameters of Thevenin (TH) equivalent system in pu are given in Table II for several DG locations.

The optimum DG angle for a low annualized fuel cost is set by the $\mathrm{R} / \mathrm{X}$ ratio of the line. It is found to be approximately 1.85 and 1.82 for the simplified test system and the actual test system, respectively. The optimum power factors are thus 0.88 lagging for the simplified test system and 0.87 lagging for the actual test system. In those cases, the reactive power limits are not violated as have been explained in Section II.

It is seen from Table II that the changes in voltage sensitivity $s_{v}$ for different DG locations are relatively small. In other words, the variation of the optimal DG operating angle with respect to the variation of the DG placement is not significant. Note that the optimal operating power factor depends on the relation between total annual fuel cost and total annual ownership cost.

TABLE II

DETERMINATION OF SENSITIVITY RATIO

\begin{tabular}{|c|c|c|c|c|c|}
\hline \multicolumn{7}{|c|}{ Simplified system } \\
\hline $\begin{array}{c}\text { Distance of DG } \\
\text { from the substation }\end{array}$ & R (TH) & $\mathbf{X}$ (TH) & $\begin{array}{c}\boldsymbol{\alpha}_{\boldsymbol{D G}} \\
\text { (rad) }\end{array}$ & $\begin{array}{c}\boldsymbol{\theta}_{\boldsymbol{D G}} \\
\text { (rad) }\end{array}$ & $\boldsymbol{s}_{\boldsymbol{v}}$ \\
\hline $48 \mathrm{~km}$ & 0.0523 & 0.0282 & -0.0243 & -0.5193 & 1.8524 \\
$46 \mathrm{~km}$ & 0.0551 & 0.0298 & -0.0248 & -0.5201 & 1.8512 \\
$44 \mathrm{~km}$ & 0.0580 & 0.0313 & -0.0251 & -0.5207 & 1.8496 \\
$42 \mathrm{~km}$ & 0.0608 & 0.0329 & -0.0253 & -0.5215 & 1.8473 \\
$40 \mathrm{~km}$ & 0.0637 & 0.0345 & -0.0254 & -0.5216 & 1.8473 \\
\hline \multicolumn{7}{|c|}{ Actual system } \\
\hline Distance of DG & R (TH) & $\mathbf{X}$ (TH) & $\boldsymbol{\alpha}_{\boldsymbol{D G}}$ & $\boldsymbol{\theta}_{\boldsymbol{D G}}$ & $\boldsymbol{s}_{\boldsymbol{v}}$ \\
from the substation & \multicolumn{7}{|c|}{ (rad) } & (rad) & \\
\hline $48 \mathrm{~km}$ & 0.0534 & 0.0293 & -0.0213 & -0.5237 & 1.8203 \\
$46 \mathrm{~km}$ & 0.0562 & 0.0309 & -0.0217 & -0.5242 & 1.8198 \\
$44 \mathrm{~km}$ & 0.0591 & 0.0325 & -0.0219 & -0.5246 & 1.8190 \\
$42 \mathrm{~km}$ & 0.0620 & 0.0342 & -0.0220 & -0.5249 & 1.8180 \\
$40 \mathrm{~km}$ & 0.0649 & 0.0357 & -0.0220 & -0.5249 & 1.8181 \\
\hline
\end{tabular}

B. Optimal Size and Placement of DG Using the Algebraic Approach

In this section, we will demonstrate how the proposed algebraic approach determines the size and location of the DG in a distribution feeder without any laterals. Consider the simplified test system where the required reference voltage is 0.94 p.u. When there is no DG in the system, for the given loading, the minimum voltage was approximately $0.92 \mathrm{pu}$, which is outside the voltage limits. Thus, the system needs extra support from the DG. By applying the algorithm shown in Fig. 5 using the route of possible Solution 1, the solutions for the DG size and location are obtained as $\left|I_{D G}\right|=0.1929 \mathrm{pu}$ and $k=1.05 \mathrm{~km}$, respectively. As discussed in Section III-D, it is necessary to verify that the voltage at the local minimum, $x_{m}$, is also within the required boundaries. By solving the equation $\left.\frac{\partial \mid V^{\prime}(x)}{\partial x}\right|_{x=x_{m}}=0$, we obtain $x_{m}$ to be $3.0 \mathrm{~km}$. Then, by substituting $x_{m}$ into (19), (21) and (22), we obtain that the voltage $\left|V^{\prime}\left(x_{m}\right)\right|$ is greater than the minimum reference voltage, and thus the solution meets the requirement specified. For this case study, load flow analysis has shown that the difference between $I_{L}^{\prime}$ and $I_{L}$ is less than $4 \%$. In other words, the DG integration for boosting the voltage from 0.92 p.u. to $0.94 \mathrm{pu}$ (as in our test case) will cause a small change in the load current.

A similar approach can be applied for different reference voltage levels. For demonstration, we present several cases with different requirements for the lower voltage limits of 0.95 $\mathrm{pu}, 0.96 \mathrm{pu}$, and $0.97 \mathrm{pu}$. Our objective here is to find a suitable DG location with the minimum DG rating at constant power factor to satisfy the specified minimum voltage constraint, $V_{r}$. Among several DG solutions which could satisfy the constraint $V_{r}$, a search is carried out to determine the most suitable DG location where the required DG rating is minimized. Fig. 7 shows the voltage and current profiles of the feeder without laterals. As can be seen from the voltage profiles, the required DG penetration increases with the increase of the voltage reference value. On the other hand, the current flow in the feeder decreases with the increase of the DG penetration level. This implies that the inclusion of DG can also benefit the power utilities by reducing power losses in the system.

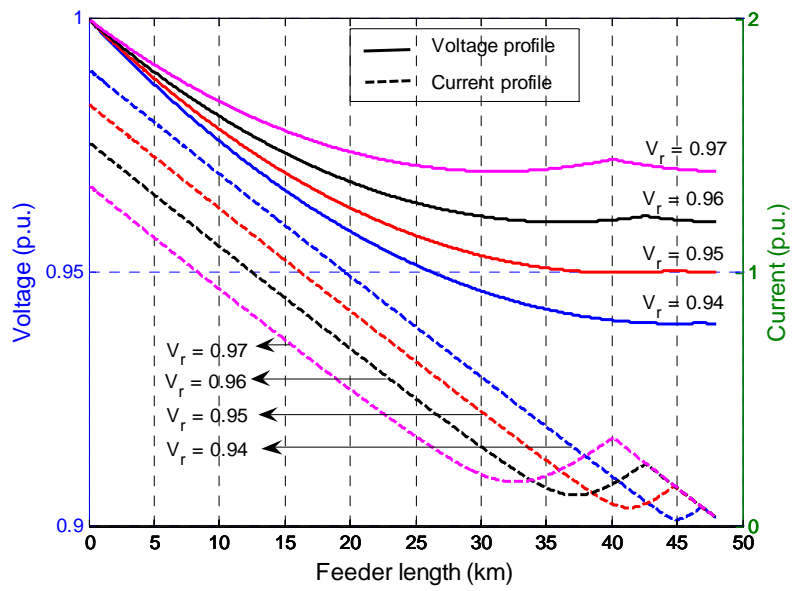

Fig. 7: Voltage and current profiles of the system with optimal DG size and location for different reference voltages

Table III shows the summary of the results obtained for different voltage thresholds by the proposed method. Location of the DG is expressed in terms of the distance from the source substation, and the size of the DG is in kVA. From Table III, we can see that the required size of the DG increases as the value of voltage reference increases. The best location of the DG moves from remote end towards the source substation as the reference voltage increases.

In Table III, DG unit is presented with computed size; however in real life, if this size is not available, the next 
available DG size will be selected. For example, the reference voltage of 0.94 p.u. indicating the need to have $144.7 \mathrm{kVA}$ can easily be met by $150 \mathrm{kVA}$ if that size is available.

$$
\text { TABLE III }
$$

OPTIMAL DG SizE AND LOCATION FOR DIFFERENT VOLTAGE LEVELS

\begin{tabular}{|c|c|c|}
\hline Reference voltage & DG size & DG location \\
\hline $\mathbf{0 . 9 4}$ p.u. & $144.7 \mathbf{~ k V A}$ & $46.8 \mathbf{~ k m}$ \\
\hline $\mathbf{0 . 9 5}$ p.u. & $292.2 \mathrm{kVA}$ & $44.8 \mathbf{~ k m}$ \\
\hline 0.96 p.u. & $458.3 \mathrm{kVA}$ & $42.6 \mathbf{~ k m}$ \\
\hline 0.97 p.u. & $650.0 \mathrm{kVA}$ & $40.1 \mathrm{~km}$ \\
\hline
\end{tabular}

From Table III, we observe the variation of DG size and location for four different reference voltages. When the reference voltage increases from 0.94 p.u. to 0.97 p.u., the required value of the DG size increases, but the distance from the DG location to the Smithton substation decreases. This can be explained by the fact that when the reference voltage is low, only the voltage at points close to the remote end fail the requirements, and a DG is installed close to the remote end. It is more efficient to place the DG closer to the remote end, so that the weak area can be supported. However, as the reference voltage increases to a higher level, the area of weak voltage which requires support from the DG becomes larger. Therefore, in this case, placing the DG further away from the remote end represents the best option for solving the voltage problem, as a wider area of the network can be benefitted from the DG installation.

In many cases, a decision regarding the DG installation is made considering operating and capital costs as one of the major factors balanced against the technical voltage requirements. In this paper, however, the technical aspects associated with improving voltage support via the use of a single DG are investigated and the costs of this solution are minimized by finding the lowest $\mathrm{kVA}$ solution at optimum power factor.

The methodology proposed is only applicable to synchronous type DG which can be renewable (e.g. biomass, biodiesel, mini-hydro) or non-renewable (e.g. diesel, gas, steam) and has the capability of operating as a variable power factor DG. The feature of the proposed approach is that it is a generalized approach applicable for any type of synchronous DG which is schedulable and can operate at a power factor specified by the user or DG owner. The aim of this study has been to develop an insightful solution to the DG placement, sizing and voltage control for simple cases. The equations developed show how the solution depends on certain parameters. For the case of a utility investing in DG for the sake of short term voltage support in a single line, single DG case is often applicable. Of course for more complex systems with multiple DG units, full optimization is always an option but would need a full set of sensitivity studies to develop an understanding of the solution.

\section{CONCLUSIONS}

In this paper, a simple but effective tool is developed to use for conceptual design and analysis of distribution system expansion with a DG system. The advantage of the proposed method is that it can give a quick estimation of DG parameters (such as optimal operating angle, size and location of a DG system) in radial networks. The size and location of a DG system have been optimized for maximizing the voltage support in uniformly loaded distribution networks. In the search for optimal size and location of the DG, continuous variables are used, which tend to converge faster to a more accurate solution compared to the discrete variables normally used in numerical approaches. A method to determine an optimal operating angle of the DG is developed based on the voltage sensitivity of lines. This paper has also developed an analytical method based on algebraic equatons to determine the most suitable DG size and location for a required level of voltage improvement. Simulations are carried out on a practical test system and results presented. The results show that the DG of optimal size located at an optimal location in the network can solve the problem of achieving a voltage level in a distribution system that satifies the voltage requirement. In practice, the choice of DG location to support the voltage profile could be limited. The proposed method shows the usefulness for conceptual use of DG for voltage support and provides the most suitable parameters of a DG system, which will benefit the network.

\section{APPENDIX}

- In the case of no DG:

$$
\begin{aligned}
& D\left\{\begin{array}{l}
V_{S}\left[-\sin (n) b\left(e^{w}+e^{-w}\right)+\cos (n) a\left(e^{w}-e^{-w}\right)\right] \\
\left.+|\rho| I_{S} \mid\left[\begin{array}{l}
e^{w} a \cos \left(\theta_{\rho}+\theta_{S}+n\right)-e^{w} b \sin \left(\theta_{\rho}+\theta_{S}+n\right) \\
+e^{-w} a \cos \left(\theta_{\rho}+\theta_{S}-n\right)+e^{-w} b \sin \left(\theta_{\rho}+\theta_{S}-n\right)
\end{array}\right]\right\} \\
\frac{\partial|V(x)|}{\partial x}=
\end{array}\right. \\
&+E\left\{\begin{array}{l}
V_{S}\left[\cos (n) b\left(e^{w}-e^{-w}\right)+\sin (n) a\left(e^{w}+e^{-w}\right)\right] \\
\left.+|\rho|\left|I_{S}\right|\left[\begin{array}{l}
e^{w} a \sin \left(\theta_{\rho}+\theta_{S}+n\right)+e^{w} b \cos \left(\theta_{\rho}+\theta_{S}+n\right) \\
+e^{-w} a \sin \left(\theta_{\rho}+\theta_{S}-n\right)-e^{-w} b \cos \left(\theta_{\rho}+\theta_{S}-n\right)
\end{array}\right]\right\}
\end{array}\right. \\
& 2 \sqrt{D^{2}+E^{2}}
\end{aligned}
$$

where, $\gamma=a+j b, \rho=|\rho| \angle \theta_{\rho}, I_{S}=\left|I_{S}\right| \angle \theta_{S}, I_{D G}=\left|I_{D G}\right| \angle \theta_{D G}$

$$
\begin{aligned}
w= & a(x-L) \text { and } n=b(x-L) \\
D= & \frac{1}{2}\left|\rho \| I_{S}\right|\left[e^{w} \cos \left(\theta_{\rho}+\theta_{S}+n\right)-e^{-w} \cos \left(\theta_{\rho}+\theta_{S}-n\right)\right] \\
& +\frac{1}{2} V_{S} \cos n\left(e^{w}+e^{-w}\right) \\
E= & \frac{1}{2}\left|\rho \| I_{S}\right|\left[e^{w} \sin \left(\theta_{\rho}+\theta_{S}+n\right)-e^{-w} \sin \left(\theta_{\rho}+\theta_{S}-n\right)\right] \\
& +\frac{1}{2} V_{S} \sin n\left(e^{w}-e^{-w}\right)
\end{aligned}
$$

- In the case when DG is integrated into the system: For $x_{0} \leq x \leq x_{k}$, 


$$
\begin{aligned}
& \left.F\left\{\begin{array}{l}
V_{S}\left[-\sin (n) b\left(e^{w}+e^{-w}\right)+\cos (n) a\left(e^{w}-e^{-w}\right)\right] \\
+|\rho| I_{S}\left[\begin{array}{l}
e^{w} a \cos \left(\theta_{\rho}+\theta_{S}+n\right)-e^{w} b \sin \left(\theta_{\rho}+\theta_{S}+n\right) \\
+e^{-w} a \cos \left(\theta_{\rho}+\theta_{S}-n\right)+e^{-w} b \sin \left(\theta_{\rho}+\theta_{S}-n\right)
\end{array}\right]
\end{array}\right]\right\} \\
& \frac{\partial\left|V^{\prime}(x)\right|}{\partial x}=\frac{+G\left\{\begin{array}{l}
V_{S}\left[\cos (n) b\left(e^{w}-e^{-w}\right)+\sin (n) a\left(e^{w}+e^{-w}\right)\right] \\
\left.+|\rho| I_{S}\left[\begin{array}{l}
e^{w} a \sin \left(\theta_{\rho}+\theta_{S}+n\right)+e^{w} b \cos \left(\theta_{\rho}+\theta_{S}+n\right) \\
+e^{-w} a \sin \left(\theta_{\rho}+\theta_{S}-n\right)-e^{-w} b \cos \left(\theta_{\rho}+\theta_{S}-n\right)
\end{array}\right]\right\}
\end{array}\right.}{2 \sqrt{F^{2}+G^{2}}}
\end{aligned}
$$

where, $z_{L}=\left|z_{L}\right| \angle \theta_{z}$

$$
\begin{aligned}
F= & \frac{1}{2} V_{S} \cos n\left(e^{w}+e^{-w}\right)+(L-k)\left|z_{L}\right|\left|I_{D G}\right| \cos \left(\theta_{z}+\theta_{D G}\right) \\
& +\frac{1}{2}\left|\rho \| I_{S}\right|\left[e^{w} \cos \left(\theta_{\rho}+\theta_{S}+n\right)-e^{-w} \cos \left(\theta_{\rho}+\theta_{S}-n\right)\right] \\
G= & \frac{1}{2} V_{S} \sin n\left(e^{w}-e^{-w}\right)+(L-k)\left|z_{L} \| I_{D G}\right| \sin \left(\theta_{z}+\theta_{D G}\right) \\
& +\frac{1}{2} \mid \rho \| I_{S}\left[\left[e^{w} \sin \left(\theta_{\rho}+\theta_{S}+n\right)-e^{-w} \sin \left(\theta_{\rho}+\theta_{S}-n\right)\right]\right.
\end{aligned}
$$

- For $x_{k} \leq x \leq x_{L}$

$$
\begin{aligned}
H & \left.\left\{\begin{array}{l}
V_{S}\left[-\sin (n) b\left(e^{w}+e^{-w}\right)+\cos (n) a\left(e^{w}-e^{-w}\right)\right] \\
\left.+|\rho| I_{S} \mid \begin{array}{l}
e^{w} a \cos \left(\theta_{\rho}+\theta_{S}+n\right)-e^{w} b \sin \left(\theta_{\rho}+\theta_{S}+n\right) \\
+e^{-w} a \cos \left(\theta_{\rho}+\theta_{S}-n\right)+e^{-w} b \sin \left(\theta_{\rho}+\theta_{S}-n\right)
\end{array}\right] \\
-\left|z_{L}\right|\left|I_{D G}\right| \cos \left(\theta_{z}+\theta_{D G}\right)
\end{array}\right]\right\} \\
& +I\left\{\begin{array}{l}
V_{S}\left[\cos (n) b\left(e^{w}-e^{-w}\right)+\sin (n) a\left(e^{w}+e^{-w}\right)\right] \\
\left.+|\rho|\left|I_{S}\right|\left[\begin{array}{l}
e^{w} a \sin \left(\theta_{\rho}+\theta_{S}+n\right)+e^{w} b \cos \left(\theta_{\rho}+\theta_{S}+n\right) \\
+e^{-w} a \sin \left(\theta_{\rho}+\theta_{S}-n\right)-e^{-w} b \cos \left(\theta_{\rho}+\theta_{S}-n\right)
\end{array}\right]\right\} \\
-\left|z_{L}\right|\left|I_{D G}\right| \sin \left(\theta_{z}+\theta_{D G}\right)
\end{array}\right]
\end{aligned}
$$

where

$$
\begin{aligned}
H= & \frac{1}{2} V_{S} \cos n\left(e^{w}+e^{-w}\right)+(L-x) z_{L} \| I_{D G} \mid \cos \left(\theta_{z}+\theta_{D G}\right) \\
& +\frac{1}{2}\left|\rho \| I_{S}\right|\left[e^{w} \cos \left(\theta_{\rho}+\theta_{S}+n\right)-e^{-w} \cos \left(\theta_{\rho}+\theta_{S}-n\right)\right] \\
I= & \frac{1}{2} V_{S} \sin n\left(e^{w}-e^{-w}\right)+(L-x)\left|z_{L} \| I_{D G}\right| \sin \left(\theta_{z}+\theta_{D G}\right) \\
& +\frac{1}{2}\left|\rho \| I_{S}\right|\left[e^{w} \sin \left(\theta_{\rho}+\theta_{S}+n\right)-e^{-w} \sin \left(\theta_{\rho}+\theta_{S}-n\right)\right]
\end{aligned}
$$

\section{ACKNOWLEDGMENT}

The authors gratefully acknowledge the support and cooperation of Aurora Energy personnel in providing data and advice on the operation of distribution systems.

\section{REFERENCES}

[1] D. Q. Hung, N. Mithulananthan, and R. C. Bansal, "Analytical Expressions for DG Allocation in Primary Distribution Networks", IEEE Transactions on Energy Conversion, Vol. 25, No. 3, September 2010, pp. 814-820.

[2] E. Carpaneto, G. Chicco, and J. S. Akilimali, "Branch Current Decomposition Method for Loss Allocation in Radial Distribution
Systems with Distributed Generation", IEEE Transactions on Power Systems, Vol. 21, No. 3, August 2006. pp. 1170-1179.

[3] M. L. da Silva, L. C. Nascimento, M. Augusto da Rosa, D. Issicaba, and J. A. P. Lopes, "Distributed Energy Resources Impact on Distribution System Reliability Under Load Transfer Restrictions", IEEE Transactions on Smart Grid, Vol. 3, No. 4, December 2012, pp. 20482055.

[4] M.A. Kashem, and G. Ledwich; "Multiple Distributed Generators for Distribution Feeder Voltage Support", IEEE Transactions on Energy Conversion, Sept. 2005, Vol. 20, Issue 3, pp. 676-684.

[5] P.A. Daly; J. Morrison; "Understanding the Potential Benefits of Distributed Generation on Power Delivery Systems", Rural Electric Power Conference, 2001, 29 April-1 May 2001, pp. A2/1 - A213.

[6] P.P. Barker, and R.W. de Mello, "Determining the Impact of Distributed Generation on Power Systems: Part 1 - Radial Distribution Systems", 2000 IEEE Power Engineering Society Summer Meeting, Seattle, Washington, 2000, pp. 1645-1656.

[7] Dai; Y. Baghzouz; "On the Voltage Profile of Distribution Feeders with Distributed Generation", Power Engineering Society General Meeting, 2003, 13-17 July 2003

[8] M.A. Kashem; G. Ledwich; "Distributed Generation as Voltage Support for Single Wire Earth Return Systems", IEEE Transactions on Power Delivery, July 2004, Vol. 19, Issue 3, pp. 1002 - 1011.

[9] W. El-Khattam, K. Bhattacharya, Y. Hegazy, and M.M.A. Salama, "Optimal Investment Planning for Distributed Generation in a Competitive Electricity Market", IEEE Transactions on Power Systems, Aug. 2004, Vol. 19, Issue 3, pp. $1674-1684$.

[10] G. Celli, E. Ghiani, S. Mocci, and F. Pilo, "A Multiobjective Evolutionary Algorithm for the Sizing and Siting of Distributed Generation”, IEEE Transactions on Power Systems, May 2005, Vol. 20, Issue 2, pp. $750-757$.

[11] W. El-Khattam, Y.G. Hegazy, and M.M.A. Salama, "An Integrated Distributed Generation Optimization model for Distribution System Planning”, IEEE Transactions on Power Systems, May 2005, Vol. 20, Issue 2, pp. $1158-1165$

[12] Q. Hung, and N. Mithulananthan, "Multiple Distributed Generator Placement in Primary Distribution Networks for Loss Reduction", IEEE Transactions on Industrial Electronics, Vol. 60, No. 4, April 2013, pp. 1700-1708.

[13] M. F. Akorede H. Hizam I. Aris M. Z. A. Ab Kadir, "Effective Method for Optimal Allocation of Distributed Generation Units in Meshed Electric Power Systems", IET Generation, Transmission and Distribution, 2011, Vol. 5, Issue 2, 2011, pp. 276-287.

[14] R. Caire, N. Retiere, E. Morin, M. Fontela, and N. Hadjsaid, "Voltage Management of Distributed Generation in Distribution Networks", Power Engineering Society General Meeting, 2003, IEEE, 13-17 July 2003, Vol. 1, pp. $282-287$.

[15] "Synchronous Machines", Mulukutla S. Sarma, New York: Gordon and Breach, Science Publishers, Inc., 1979, Chapter VII Excitation Systems.

[16] V. R. Pandi, H. H. Zeineldin, W. Xiao, "Determining Optimal Location and Size of Distributed Generation Resources Considering Harmonic and Protection Coordination Limits", IEEE Trans. On Power Systems, Vol. 28, No. 2, pp. 1245-1254, May 2013.

[17] M. F. Shaaban, Y. M. Atwa, and E. F. El-Saadany, "DG Allocation for Benefit Maximization in Distribution Networks", IEEE Trans. On Power Systems, Vol. 28, No. 2, pp. 639-649, May 2013.

[18] S.-H. Lee, and J.-W. Park, "Selection of Optimal Location and Size of Multiple Distributed Generations by Using Kalman Filter Algorithm", IEEE Trans. On Power Systems, Vol. 24, No. 3, pp. 1393-1400, Aug 2009.

[19] P. Pachanapan, O. Anaya-Lara, A. Dysko, and K. L. Lo, “Adaptive Zone Identification for Voltage Level Control in Distribution Networks with DG”, IEEE Trans. On Smart Grid, Vol. 3, No. 4, pp. 1594-1602, Dec 2012 .

[20] P.-C. Chen, R. Salcedo, Q. Zhu, F. de Leon, D. Czarkowski, Z.-P. Jiang, V. Spitsa, Z. Zabar, and R. E. Uosef, "Analysis of Voltage Profile Problems due to the Penetration of Distributed Generation in LowVoltage Secondary Distribution Networks", IEEE Trans. On Power Delivery, Vol. 27, No. 4, pp. 2020-2028, Oct 2012.

[21] H. A. Hejazi, A. R. Araghi, B. Vahidi, S. H. Hosseinian, M. Abedi, and H. Mohsenian-Rad, "Independent Distributed Generation Planning to Profit both Utility and DG Investors", IEEE Trans. On Power Systems, Vol. 28, No. 2, pp. 1170-1178, May 2013

[22] P. S. Georgilakis, and N. D. Hatziargyriou, "Optimal Distributed Generation Placement in Power Distribution Networks: Models, 
Methods, and Future Research”, IEEE Trans. On Power Systems, Vol. 28, No. 3, pp. 3420-3428, Aug 2013.

[23] W. H. Kersting, "Distribution System Analysis", CRC Press, 2012.

[24] V. Cecchi, M. Knudson, K. Miu, C. Nwankpa, "A Non-Uniformly Distributed Parameter Transmission Line Model", North American Power Symposium (NAPS), 9-11 Sept, 2012.

[25] M.J.D. Powell, "Numerical Methods for Nonlinear Algebraic Equations", Science Publishers Ltd., 1970. 